\title{
Problems of Coordination of High-Tech Enterprises Strategies in Implementation of Innovative Technologies
}

\author{
Aleksandr Mikhaylovich Batkovskiy ${ }^{1}$ \\ Vladislav Valerievich Klochkov² \\ Elena Georgievna Semenova ${ }^{3}$ \\ Alena Vladimirovna Fomina ${ }^{1}$ \\ Natalya Vladimirovna Cherner ${ }^{4}$ \\ ${ }^{1}$ Joint Stock Company "Central Research Institute of Economy, Management and Information Systems "Electronics", \\ Moscow, Russian Federation \\ ${ }^{2}$ V.A. Trapeznikov Institute of Control Sciences, Russian Academy of Sciences, Moscow, Russian Federation \\ ${ }^{3}$ The Department of Innovation and Quality Management, St. Petersburg State University of Aerospace Instrumentation, \\ St. Petersburg, Russian Federation \\ ${ }^{4}$ The Department of Industrial Management, Moscow Aviation Institute, National Research University, Moscow, Russian Federation \\ Email: batkovskiy_a@instel.ru
}

Doi:10.5901/mjss.2015.v6n4s4p172

\begin{abstract}
Implementation of innovative technologies in cooperative enterprises is complicated by the fact that the innovative strategy of an enterprise would not be supported by its partners. As a result, even a generally profitable innovative project may remain unrealized because the partners will not take risks of investing into specific assets. Similar problems occur in connection with launch of manufacturing of high-tech components for sophisticated products (particularly, as part of import substitution). The article suggests a simple game theory model, which illustrates the problems of coordination of partner enterprises' strategies in implementation of innovative products. Unlike well-known models, this model takes into account the specific nature of high-tech industries, including the cost structure of the product life cycle, which affects costs and losses. This model may be used for quantitative estimations in the course of substantiation of innovative technologies implementation strategies in certain hightech industries. The suggested model helped to analyze the efficiency of various mechanisms of enterprise strategies coordination in implementation of interrelated innovative technologies. The article studies the market mechanisms of coordination, as well as the mechanisms of compensations to members of unimplemented innovative projects. We also analyzed the impact of institutional factors (such as trust in the systems integrator of the project, transparency of innovative development strategy) on the efficiency of such mechanisms. Special attention is paid to the specific features of the militaryindustrial complex, the problems of which are the most challenging in this respect. We made a conclusion about the inevitable need for the centrally controlled implementation of innovative technologies by Russian high-tech industries, which fulfill largescale modernization and import substitution programs. This suggests construction of integral innovative technological chains in state corporations, making their links independent. The article comes up with recommendations focusing on enhancement of the market incentives for participation of independent small and medium-sized enterprises in innovative projects of large hightech corporations.
\end{abstract}

Keywords: innovative technologies; risk; coordination; network organizational structures; vertical integration; compensation.

\section{Introduction}

\subsection{Introduction into the problem}

Today, the Russian high-tech industry is facing the issues of large-scale technical upgrade and accelerated import substitution (particularly, in production of strategically important products and components). High hopes are being put on involvement of small and medium-sized enterprises in manufacturing of advanced products, implementation of innovative technologies. The military-industrial complex is not an exception. Despite its specific nature (critical supplies for military needs, high state secret security level etc.), the Russian military-industrial complex has significant reserves for 
involvement of private sector, small and medium-size enterprises in supply of high-tech components and production services. Suppliers of the Russian military-industrial complex obtain obvious benefits, including, first of all, significant volumes of orders with sustainable financing (Bogdanova, L.S. et al., 2006). However, the real pace of development of the innovative business environment of major enterprises in the Russian military-industrial complex is not sufficient, preventing import substitution in quite a few segments of the high-tech components market. Ushenin (Ushenin, Y.S., 2015) gives some examples, when, on the one hand, there is a significant demand for products on the part of the militaryindustrial complex, and, on the other hand, Russian enterprises able to manufacture relevant products of appropriate quality at lower prices as compared with foreign suppliers. However, barriers still exist between potential suppliers and customers, and this article analyzes their reasons and the ways to overcome them.

\subsection{Importance of the issue}

The present stage of development of the global high-tech industry is described by the overall completion of transition to the network organizational structures, while such transition is still under way in Russia (Batkovskiy, A.M. et al., 2014). In particular, such strategy of reforms of the organizational structure forms the basis of the 'Development of the Aviation Industry in 2013-2025' State Program of the Russian Federation (Gosudarstvennaya programma, 2013). Enterprises abandon complete production cycle (i.e. manufacturing and assembly of all basic components on a single site), selecting the role of either the systems integrator of finished goods, or specialized supplier of any components or production services operating for the benefit of many systems integrators.

Such changes in the industry's structure become even more significant in the light of innovative development of technologies (Shcherbakov, D.S., 2010). According to Kustova (Kustova, M.V., 2014), a parent company, being a systems integrator of finished goods, becomes surrounded by the system of small and medium-sized enterprises, which comprise the parent enterprise's innovative infrastructure. Such trend is clearly illustrated by growth in the quantity of small and medium-sized enterprises in the U.S. aviation industry during the period of formation of the industry's structure, see Figure 1 (Aircraft Manufacturing, 2009).

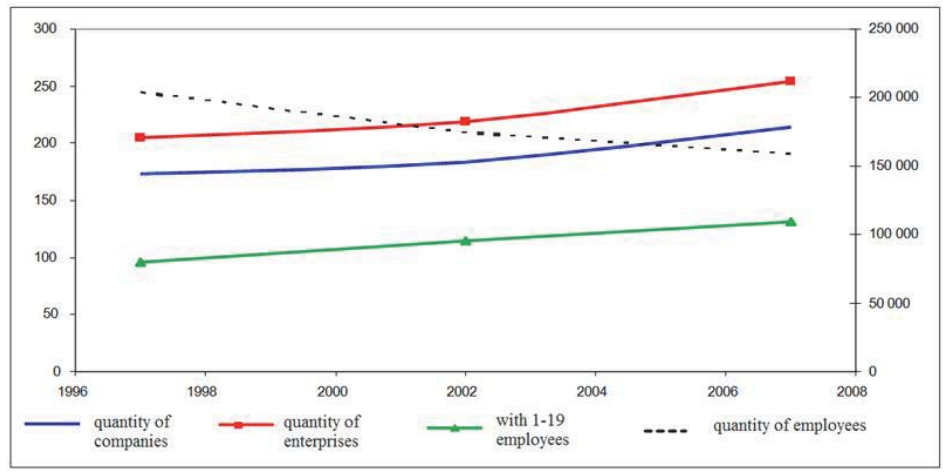

Figure 1. Change in the quantity of companies of the U.S. aircraft industry, 1997-2007

We may see that the quantity of companies and enterprises in the Russian aircraft industry was increasing during 19972007 despite consolidation of final producers. We would like to emphasize that such increase in the quantity of companies took place due to significant reduction in the quantity of employees during the period rather than due to increase in the total quantity of employees in the industry. The quantity of enterprises with 1-19 employees increased up to $50 \%$.

The environment of large high-tech enterprises, comprising small and medium-sized specialized enterprises, is known as the 'business fabric', which means that a parent enterprise operates within the environment of such partner enterprises, but they can also be the partners of other major producers, even competitors (which is typical for network organizational structures). By implementing innovative technologies, purchasing new equipment etc., each specialized producer in the distributed (matrix, network) industry structures relies on the support of its innovation policy by other parties involved in manufacturing of finished goods. Otherwise, investments in new technologies and equipment will not yield the expected return and will not be efficient. Moreover, innovative and traditional technologies are often alternative 
and incompatible, and transition to innovative technologies is associated with the irrecoverable loss of the possibility to continue work using the previous technologies (to be more precise, with extremely high recovery costs) (Meyers, F., and Stephens, M., 2003). Such risks result in more cautious and conservative behavior of investors and owners of enterprises, which blocks innovative development of many high-tech industries.

\section{Literature Review}

Efficiency and risks of transition of the high-tech industry to the network organizational structure are analyzed in numerous works, such as (Daft, R., 2004), (Glazyev, S.Yu., 1993), (Comer, G., 2001), (Knobel, A.Yu., 2010), (Krayewski, L. and Ritzman, L., 2004), (Policinskaya, E.V et al., 2014), (Volkov, O.I., and Devyatkin, O.V., 2004). Kustova (Kustova. M.V., 2014) describes the problems of creation of the innovative infrastructure, which are reduced mostly to various risks inherent to network organizational structures, illustrating them by the case of Saturn (Research and Production Association), Russia's major developer and producer of aircraft engines and gas turbines, as well as its partners. In particular, the author mentions the risk of indirect competition with other systems integrators, on which specialized suppliers may also focus. However, these problems are hardly related to innovative development (Temple Black, J. and Hunter, S.L., 2003). They are typical of the network structures on each stage of the technologies' innovative cycle, not necessarily in high-tech industries. It is important to analyze specific problems of innovative development, which are appropriate for state-of-the-art organizational structures of high-tech enterprises and industries.

Expediency of flexible changes in the organizational structure of industries throughout the innovative cycle of industrial technologies is justified by Russian and foreign economists, e.g. Acemoglu (Acemoglu, D. et al., 2002b), (Acemoglu, D. et al., 2002a). These studies come to identical conclusions using different methodologies: on the initial phases of development of the new technology wave, vertical integration would be more expedient, and later, when more and more innovative technologies are implemented, it would give way to the network structures and outsourcing (Merriam-Webster Online, 2005). Interrelation of innovative technological development and industry-level organizational structures was studied by Dementiev (Dementiev, V.E., 2012); however, in his work he does not deal with the issues of coordination of enterprises' innovative policies on the micro-level.

The problems and mechanisms of coordination of innovative policies of independent participants were the most deeply investigated issues in modern economics with respect to development of the so called 'freely redistributable software' (free or open-source software). Dalle, Julien and David (Dalle, J-M., and Julien, N., 2003), (Dalle, J-M., and David, P., 2008) deal with the issues of coordination of efforts between independent developers of software modules. They point out that the incentives for implementation of truly innovative solutions may be weak, and all cooperation parties limit themselves to incremental, small improvements. Probably, the article by Bonardi and Warin (Bonardi, J.-P., and Warin, T., 2007) is the closest study to the above work in the methodical aspect. It also builds a game-theory model of the parties' behavior in respect of open-source software upgrade. But, unlike this work, in this article the players choose the level of innovative efforts in the game with the "nature", and the states of the "nature" determine whether new development would represent a radical innovation or an incremental improvement. The game-theory model described below provides for other preconditions. Besides, special emphasis is placed on analysis of the components of payoff matrices with account for the specific nature of the military-industrial complex in order to identify its impact on preferable strategies.

The models for approval of innovation policies of cooperating enterprises in the high-tech industry were partially developed by Dutov and Klochkov (Dutov, A.V., and Klochkov, V.V., 2013). These are the game-theory models, which determine the terms when the innovative strategy will have the prevailing nature, the guaranteeing nature, or, finally, when the innovative strategy will be inexpedient (dominated) for the party involved in the high-tech product creation process. The article ultimately justifies centralized planning of technological innovative development in the industry, and suggests a game-theory approach to assessment of losses resulting from inconsistent solutions independently made by developers of separate components of sophisticated technical systems or by researchers in various fields of applied science. This work places emphasis on the above issue in the field of production (rather than development) of high-tech products.

\section{Methods}

\subsection{Hypotheses and the research plan}

Analysis of the above practical issues allows to formulate a hypothesis according to which the high risk of investments in 
specific assets (in terms of the institutional economics) remains the main obstacle to establishment of small and mediumsized innovative enterprises in the environment of major enterprises of the military-industrial complex. This means that the problem of coordination between the systems integrators' and suppliers' development strategies emerges in the course of implementation of innovative technologies, which may be analyzed with the help of economic and mathematical tools. Besides, such economic and mathematical model should allow to analyze the efficiency of alternative mechanisms of such coordination.

\subsection{Description (based on the game theory) of implementation of innovative technologies in the distributed production systems}

Let's consider making a decision on implementation of innovative technologies by a specialized supplier of any type of components for sophisticated finished goods within the framework of the game of such enterprise and the "nature", which is understood as other participants contributing to creation of the sophisticated product. Interaction between an individual and the society, particularly in the course of financing of public goods production, are considered in a similar manner in the economic theory. According to the generally accepted classification of games, such interaction may be deemed as the game with the nature (i.e. the game with a "partner" of a significantly larger scale and without direct response to the player's behavior), since all the rest participants, though being of the same small scale, act independently of each other and such participant. The fact that "all the rest" comprise the same representative players, as the one under analysis within the model, is taken into account when searching for a balance after a rational strategy for this game is determined. Each party to this game has two strategies - "0", i.e. to keep from implementation of the innovative technology continuing to use the old technology, and " 1 ", i.e. to implement the innovative technology, incurring relevant capital expenditures. Figure 2 shows the payoff matrix of this game.

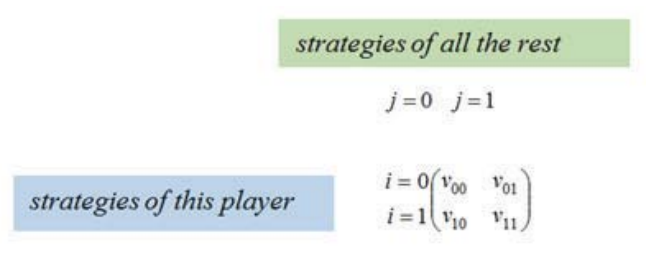

Figure 2. The payoff matrix of the game of this participant involved in creation of a sophisticated product and "all the rest"

Let's assume that the diagonal elements of this payoff matrix correlate as: $v_{11}>v_{00}$, i.e. in case of successful implementation the innovative technology provides a win for all participants. However, the off-diagonal elements which are related to the cases when a strategy of this player does not coincide with the strategy of "all the rest" may correlate with the diagonal elements and with each other differently. In the general case, the rational behavior of the player and "all the rest" may be different, subject to correlation between the elements of the payoff matrix $\left\{v_{i j}\right\}$. The "innovative" strategy $i=1$ may be:

- dominant, i.e. known as most profitable regardless of the behavior of the rest players (which ensures selection of this strategy by any players), if at the same time: $v_{10}>v_{00}$ and $v_{11}>v_{01}$;

- guaranteeing the highest win in the least favorable situation (which urges cautious players to follow this strategy), if $\min \left\{v_{10} ; v_{11}\right\}>\min \left\{v_{00} ; v_{01}\right\}$;

- neither dominant nor even guaranteeing.

In the latter case, there is a small possibility of selection of such strategy. However, it is possible, if a player adheres to the so called 'optimistic strategy' (Dubrov, A.M. et al., 2001). Despite its name, it is typical for players in a desperate situation, when they need only the most profitable result of the game. In this case, the optimistic strategy may be selected by players, for which success of an innovative project and win $v_{11}$ is the only acceptable outcome, and all other outcomes are known as unacceptable. Such producers would probably be the "innovators against their will"; however, the situation where position and win $v_{00}$ are quite acceptable for specialized suppliers and contractors, is far more common. 


\subsection{Analysis of correlation of payoff matrix elements}

Interpretation of the above conditions is required. Domination of the "innovative" strategy means that it brings a win in any case, even if it is not "supported" by other participants of creation of a sophisticated system: $v_{10}>v_{00}$.. Generally, it is possible, if a local innovation is considered in terms of the link of the technological chain, to which the considered company relates. Then it may bring a win to the innovator, e.g. due to reduced production costs of this assembly, module, unit, which is installed into the sophisticated product of a standard structure. However, quite often this is impossible, since transition to a new technological mode takes place (and such situation is relevant for many branches of the military-industrial complex). In such case, radical (not incremental) product and technological innovations require deep transformations of all used technical and organizational systems. Left driving (if it were recognized more innovative) can be an illustrative, though a telling example - it can not be introduced as an experiment for several percent of cars in the country.

In cases when a specialized innovative enterprise agrees to take part in a breakthrough innovative project, significant investments in radically new technologies and lose an opportunity to return to the previous technologies, losses are inevitable in case of failure of such project. Inequality $v_{10}<v_{00}$ holds, and the 'innovative' strategy $i=1$ is not dominant. However, it can still be guaranteeing provided that in case of the least favorable behavior of all the rest participants, it would provide to the player a larger win than the conservative strategy $i=0$. It is possible, if $\min \left\{v_{10} ; v_{11}\right\}>\min \left\{v_{00} ; v_{01}\right\}$.

Such inequality can be made more specific relying on substantive assumptions regarding characteristics of the elements of the payoff matrix $\left\{v_{i j}\right\}$. Primarily, we assume here that innovation efforts of all players complement each other since they produce not competitive, but complementary goods or services. Then $v_{11}>v_{10}$, i.e. the player would receive a bigger win, if all the rest parties involved in creation of a sophisticated product followed the innovation strategy. With such assumption, $\min \left\{v_{10} ; v_{11}\right\}=v_{10}$.

In turn, if such player remains the only player, which made no transition to the innovative technology, it would probably bear losses as compared to the situation when everyone used the conservative technology, i.e. $v_{01}<v_{00}$ and $\min \left\{v_{00} ; v_{01}\right\}=v_{01}$. This assumption is feasible due to the fact that products from different specialized suppliers are deemed complementary. Besides, if such player is the sole producer of respective components or production services, then the lack of innovative products on its behalf would result in losses of all the rest parties involved in creation of a sophisticated product, but it would suffer losses in any case, since its current products would not be demanded by the systems integrator. If, in addition to this producer, there are other producers specialized in the same components or production services, then these competitors will get a win from their enhanced market power, and this player would suffer even greater losses, being driven out of this market.

Summarizing all of the above considerations, we may conclude that any specialized producer of components or production services would suffer losses, if its strategy differs from the strategies of other players. Innovation strategy $i=1$ can be guaranteeing, if the condition $v_{10}>v_{01}$ is met. That is, the losses of this player, which unilaterally implemented radically innovative technology or started producing innovative components ("pioneer"), should be lower than the losses of the player, which alone did not make the above steps ("retrograde"). How realistic is such correlation of payoff matrix elements?

\subsection{Economic analysis of enterprises' win and loss components when implementing innovative technologies}

In order to give a meaningful answer to this question, we need to analyze the structure of wins $\left.{ }^{\left\{v_{i j}\right.}\right\}$ in more detail. At first approximation, wins can be taken as the accumulated (perhaps, discounted) profit for the period starting after the "innovative" or "conservative" strategy was selected and ending after abandonment of products of this generation. Profit estimates should take into account investment costs incurred during such period. It would seem logical that the "conservative" strategy $i=0$ does not require investments from suppliers and contractors, which are successful at the moment, since all those investments had been made before.

Let's also assume that in case of a combination of such strategies followed by this player and all the rest ones, this player would act reasonably within the selected strategy. That is, for example, if an innovative product or technology 
turned out to "be ahead of time" (which corresponds to the combination of strategies ${ }^{(i=1 ; j=0)}$ ), the player would compare existing options:

$>$ to accept an irrecoverable loss of investments in the innovative technology (or manufacturing of innovative products) $I_{\text {инн }}$ and impossibility to launch production, and to abandon this market segment; or

$>$ to make additional investments in order to return to the old technology or products in the amount of $\Delta I_{\text {возвр }}$ and to resume production under the previous technology, which would result in producer's operational profit

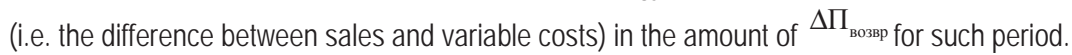

Therefore, $v_{10}=\max \left\{-I_{\text {инн }} ; \Delta \Pi_{\text {возвр }}-I_{\text {инн }}-\Delta I_{\text {возвр }}\right\}$.

Similarly, if it turns out that such player lags behind all other parties involved in creation of a sophisticated product in respect of implementation of innovative technologies or production of innovative components, then it may:

$>$ try to catch up, making the same investments $I_{\text {инн and generating operational profit }} \Delta \Pi_{\text {иннов until the end of }}$ the period;

$>$ accept abandonment of its products. Let's remind that such conservative payers would not have to make additional investments.

Therefore, $v_{01}=\max \left\{0 ; \Delta \Pi_{\text {инов }}-I_{\text {инн }}\right\}$.

\section{Results}

\subsection{Impact of various factors on the preferred innovation strategy}

Let's analyze the impact of such factors as the enterprise's background, technologic similarity of innovative products and previously manufactured products, intensity of the competition, information asymmetry and trust in the innovative project's initiator on the enterprise's tendency to select the innovation strategy.

Please note that within the framework of the above model win of the "retrograde" is reliably non-negative: $v_{01} \geq 0$, whereas $v_{10}$ can take negative values (when $\Delta \Pi_{\text {возвр }}<\Delta I_{\text {возвр }}$, which becomes especially probable, if there is little time left until the end of the production period). That is, the losses suffered by the "retrogrades", are not (at first approximation) as huge as possible losses suffered by the "pioneers". But if a small enterprise, supplier of innovative components or production services to the systems integrator, is established as a "greenfield" investment, it is not encumbered with the inertia of prior investments in traditional technologies. And if it was considered earlier that a "retrograde" win is known as a non-negative win: $v_{01}=\max \left\{0 ; \Delta \Pi_{\text {инов }}-I_{\text {ини }}\right\}$, the situation is different with regard to newly established enterprises - they would have to make investments in relevant technology anyway, even though it is old. Therefore, $v_{10}>v_{01}$ condition may also hold, making the "innovation" strategy a guaranteeing one. Once again, this relates to new, "greenfield" enterprises, only. Therefore, they (all other factors being equal) are more apt to implementation of innovative technologies (authors do not claim a credit for the novelty of this statement - coincidence with known results takes place here, which enhances trust in the authors' modeling method).

More detailed analysis of the composition and structure of required investments - both in innovative technologies $I_{\text {инн }}$, and in order to return to the previous technologies or components $\Delta I_{\text {возвр }}$-allows to make more exact conclusions on the preferred innovation strategy for the players. If a specialized enterprise in the network structure produces similar components or provides production services for several systems integrators or various finished goods, the required investments (which determine the enterprise's losses in case of the project's failure) can be relatively low when launching production of components a for new customer or the next model of finished goods. However, if under the influence of the systems integrator its "business environment" is proposed to use principally new technologies, radical technological upgrade of the whole specialized enterprise would be required; investments required for implementation of the innovative technology and, if necessary, for return to traditional technologies, will have approximately the same amount as relevant fixed assets.

A peculiar feature of high-tech enterprises, which reduces attractiveness of the innovation strategy, lies in the fact that future sales of components developed or certified upon request of parent enterprises (at the cost of significant 
investments) may be unknown to the potential supplier due to restrictions regarding disclosure of information regarding the volume of military goods production. As a result, even profit $\Pi_{\text {иннов in case of successful implementation of the whole }}$ innovative project, i.e. in balance $(i=1 ; j=1)$, remains undetermined, which does not contribute to selection of an innovation strategy.

Generally, the role of a "pioneer" may be rather more advantageous, if the factor of temporary competition is strong and producers, which failed to shift to the new technological level, may face high barriers of entry (or return) to the market of relevant components. Their competitors already possess experience in manufacturing of innovative products (which allows to reduce costs); the partners and customers of competitive suppliers already rely on the quality of relevant components or services. In terms of this model, it is expressed as follows: $\Delta \Pi_{\text {иннов }}<0$, and at least $\Delta \Pi_{\text {иннов }}<\Delta \Pi_{\text {возвр }}$. However, in this case the "innovative" strategy $i=1$ becomes a guaranteed strategy only upon fulfillment of a very strict condition: $\Delta \Pi_{\text {возвр }}-I_{\text {инн }}-\Delta I_{\text {возвр }}>0$, or $\Delta \Pi_{\text {возвр }}>I_{\text {инн }}+\Delta I_{\text {возвр }}$. That is, the operational profit of a producer, which returned to traditional products and technologies, should exceed the amount of investments in implementation of innovative technologies and return to the traditional technologies during the planning period. If such condition is not met, the "innovative" strategy will not be a guaranteeing strategy and will not be selected by a cautious investor despite the fact that the approved simultaneous selection in favor of innovations would bring a win to all of them: $v_{11}>v_{00}$. Since "all the rest" participants would argue in the same manner, the balance $(i=0 ; j=0)$ would occur, which means that implementation of the innovative technology or transition to manufacturing of innovative products under relevant terms would be blocked by conservatism of certain specialized producers in the network organizational structures.

\subsection{Analysis of efficiency of risk compensation mechanisms during implementation of innovative technologies by partner enterprises}

The systems integrator of an innovative product may, in principle, offer to suppliers and contractors an advance compensation or damage compensation guarantee in case of the innovative project's failure. How can such mechanism overcome the conservatism of suppliers and contractors? First of all, an assessment should be made in respect of the amount of investments (advance or conditional - paid out only in case of failure of the innovative project), which would have been sufficient to persuade the specialized enterprises to select the innovative strategy. They should cover at least the damages suffered by the partner enterprise in case of the innovative project's failure.

Potential damage may be assessed as a difference between the wins if the work is continued with the old technology and in case of advance implementation of new technologies by such participant $\left(v_{00}-v_{10}\right)$. Then the minimum required compensation would be equal to $C_{\min }=v_{00}-v_{10}$. Then, taking into account compensation $C \geq C_{\min }$, "pioneer's" win even in case of the innovative project's failure in general would amount to $v_{10}{ }^{\prime}=v_{10}+C \geq v_{10}+C_{\min }=v_{10}+v_{00}-v_{10}=v_{00}$, i.e. now $v_{10}{ }^{\prime} \geq v_{00}$. The "innovation" strategy $i=1$ becomes dominant, and all parties involved in creation of a sophisticated product would choose it. However, in case of advance payment of such compensations, the potential win from successful implementation of the innovative project, amounting to $\left(v_{11}-v_{00}\right)$ per average supplier, may be insufficient in order to cover the average amount of paid compensations. It is quite possible that $v_{11}-v_{00}<C_{\min }=v_{00}-v_{10}$, or $v_{00}>\frac{v_{11}+v_{10}}{2}$ (i.e. the arithmetic mean of wins in case of approved implementation of an innovative technology and in case of its unilateral implementation by such player is lower than the win when status quo is maintained). It is quite possible in case of high losses suffered by "pioneers", especially if required investments in innovative technologies $I_{\text {инн }}$ are high.

As described above, the "pioneer's" win ${ }^{10}$ is floored by the amount of investments made in the course of implementation of an innovative technology $I_{\text {инн with the reversed sign; therefore, inequality }} \frac{v_{11}+v_{10}}{2}>\frac{v_{11}-I_{\text {инн }}}{2}$ holds. If $\frac{v_{11}-I_{\text {шни }}}{2}>v_{00}$ condition is met, then inequality $v_{00}<\frac{v_{11}+v_{10}}{2}$ holds, and the win in case of successful implementation of the innovative project would be enough to cover the advance compensations. Otherwise, especially when the required 
investments in innovative technologies are comparable with the win in case of successful implementation of the

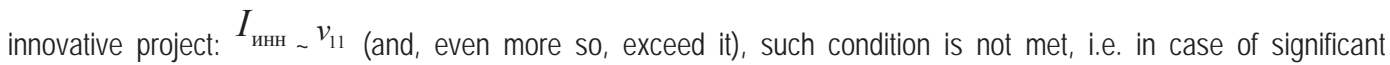
investments in the new technology, comparable with the win from its implementation, advance compensations will not provide incentives to specialized enterprises for its implementation.

It may be argued that the "fair" volume of compensation can be lower, since in order to incite suppliers and contractors to select "innovation" strategy $i=1$, usually it would be enough to make it at least a guaranteeing strategy rather than a dominant strategy, i.e. to make sure that inequality $v_{10}{ }^{\prime}=v_{10}+C \geq v_{01}$ holds. Such minimum compensation amount $C_{\min }^{\text {гарант }}=v_{01}-v_{10}$ would be lower than $C_{\min }=v_{00}-v_{10}$, since $v_{01}<v_{00}$. But in this case it is also possible that the aggregate win from successful implementation of the innovative technology throughout the whole production chain will not be enough to cover the compensations which had been paid out.

Let's look at a telling illustrative example. Let the payoff matrix of a representative specialized enterprise, supplier of components or production services, be of the following form: $\|\nu\|=\left(\begin{array}{cc}v_{00} & v_{01} \\ v_{10} & v_{11}\end{array}\right)=\left(\begin{array}{cc}5 & 1 \\ -5 & 10\end{array}\right)$. Under such conditions, the "innovation" strategy $i=1$ is neither a guaranteeing, nor, even more so, a dominant strategy. In order to transform such strategy into the dominant strategy, we need to offer to such supplier a compensation in the amount of at least $C_{\min }=v_{00}-v_{10}=5-(-5)=10$. However, the gain in the win of a representative supplier in case of success would amount to just $v_{11}-v_{00}=5$, i.e. it would not cover an advance compensation. And in order to make "innovation" strategy $i=1 \mathrm{a}$ guaranteeing strategy, compensation in the amount of at least $C_{\min }^{\text {гарант }}=v_{01}-v_{10}=6$ would be required, which would make such innovative project unprofitable for its initiator, i.e. the systems integrator of a product.

At first glance, the problems of incitement of suppliers' and contractors' transition to the innovation strategy weaken, if instead of unconditional (advanced) compensation of damage, the systems integrator offers to the partners a conditional compensation, i.e. reimbursement of damages in case of the project's failure. However, when potential suppliers and contractors possess full information about the condition and prospects of all process participants, opportunist behavior is also possible. Those who have not entered into agreements on transition to the innovative technology with the systems integrator yet, may blackmail the latter demanding much higher price for their consent than their potential damages in case of the innovative project's failure $\left(v_{00}-v_{10}\right)$. In such case, the "demand price" for their consent is higher than the "offer price" since it reflects potential losses of the systems integrator when it would have to fulfill guarantee obligations to the partners which previously agreed to implement innovative technologies. And this "demand price" will be the higher the fewer potential partners are left to be engaged by the systems integrator.

Such examples are also widely known; Udalov and Komissarov (Udalov, K.G. and Komissarov, D.S., 1994) provide a story of construction of Boeing aircraft assembly plant in Everett, Washington, United States. The land value is relatively low in this underpopulated state, especially far from large cities, and the purchase of land for plant construction did not require large costs until the last small plot, which was located in the middle of the future territory, remained to be acquired. Its owner, realizing that a large and expensive construction is planned, charged an extremely high price for his consent, and the company had to pay it. Of course, possibilities of the described blackmailing of the systems integrator by specialized producers also remain in case of advance compensations. Still, they weaken, if such type of components or production services can be supplied by several competing producers.

The suggested game-theory model allows to analyze the efficiency of intermediaries, which consolidate the needs of a significant amount of parent enterprises from various industries, as well as the offers made by many potential suppliers of components. Scale effects allow them to mitigate the risks of reduction in customers needs, as well as to reduce the price of certification procedures due to accumulation of significant experience.

\section{Discussion}

Significant part of the above issues would be eliminated if small enterprises, being the "business fabric" of a parent producer, relied on the latter and its policy. The above game situations may be considered not as single-step, but as multistep repetitive games. If the systems integrator proves that it is able, mainly, to coordinate the innovation policies of all its partners and to achieve success of innovative projects, some enterprises would consider balance ${ }^{(i=1 ; j=1)}$ as almost guaranteed - and, since it is the most profitable for many players, it will be achieved in practice. However, to this 
effect, the systems integrator itself should realize the significance of such resource as the trust by its partners. As shown above, it has quite an objective literal manifestation, allowing to get the partners (which in absence of trust would prefer the conservative strategy) interested in implementation of innovative technologies. It is usually offered to develop production, research and other capacities of small enterprises up to such an extent that refusal by the parent enterprise from their services would not be critical for them. However, "switching" between specialized suppliers and other systems integrators is possible only with respect to production of marketable and almost standardized components, which may be easily offered to other customers. But losses of specialized supplier enterprise suffered from termination of cooperation within such innovative project are inevitable when the parent enterprise acts as an innovation leader implementing radically new technologies and suggests to share risks with its environment comprising small and medium-sized companies being its "business fabric". In practice, management of largest corporations of the Russian high-tech industry is not prone to take any responsibility for the condition of its partners - which, in turn, leads to reduction of their quantity and competitiveness of component markets in the long run.

Actually, the above problems of specialized suppliers' and contractors' distrust in the systems integrator's policies, or their opportunism in respect of the parent company may be avoided. The latter may arrange production of the necessary components and production services on its own, rejecting outsourcing and specialization benefits, and returning to the vertically integrated production structure within its own enterprise. At a first glance, this takes place within one of the standard forms of cooperation between independent suppliers and customers - LTA (Long-Terms Agreements), when all necessary investments are made by the customer. However, under LTA, systems integrators order necessary components, generally from specialized suppliers, which already produce components of such type, but of different standard sizes. Therefore, the amounts of investments which the partners expose to risk under such standard contracts are low (as compared to the full amount of investment required to create relevant "greenfield" production facility). That is, the cost benefits of the network organizational structure are preserved in this case. Breakthrough technological innovations, which require radical technological upgrade of suppliers and contractors rather than just "finetuning" of existing facilities for production of one more standard size of components, are also considered here. In this case, the initiator of an innovative project would have to finance creation of a new production facility under LTA, and the network form of production organization will not generate significant benefits. That's why, "to make or to buy" dilemma under such conditions is often solved in favor of independent production of innovative components and production services.

Therefore, in order to compensate innovation risks, in most cases it will be necessary to resort to the vertical integration of technological chains for the period of change in technologies, or, at least, implementation of a large quantity of interrelated innovative technologies. Meanwhile, innovative technologies may appear in separate links of technological chains, i.e. they may have the localized rather than the generalized nature. In such cases, small and medium-sized enterprises may indeed act as generators of innovations or may be established for local innovative projects, which are then built into existing conservative technological chains.

However, in the current situation many branches of the Russian high-tech industry - aircraft, radioelectronics, shipbuilding, machine tool building - face the task of reindustrialization. Import substitution and liquidation of the gap existing between them and foreign competitors, require creation of integral innovative technological chains. Even if relevant technologies are not innovative on the global scale, they are innovative at the national level. Therefore, the situation with the national industry is identical to transition to new technologies.

According to the above formal analysis, coordinating market mechanisms may be insufficient, so relevant industrial policy should include, but not limited to plans for development of integral technological chains - e.g. within state corporations, which on this phase combine basic branches of the Russian high-tech industry, e.g., United Aircraft Corporation, United Engine Corporation, United Shipbuilding Corporation. The capacity of the command-based coordination mechanisms, which are among the few benefits of state corporations, should be applied in order to create the whole industry rather than just production facilities (Wasserman, A.A., 2015). Meanwhile, the established high-tech facilities may be vested with business independence (especially considering the fact that they would become completely independent within an appropriate network structure) - numerous in-house management mechanisms, which are intermediate between the command system and the market system, exist for that end.

\section{Conclusion}

1. Some parties involved in creation of sophisticated high-tech products, including independent small and medium-sized enterprises, may be not interested in implementation of innovative technologies and assuming innovation risks, investing into specific assets without any guarantees of support from other parties. 
2. At the early stages of new technologies' lifecycle in the industry, a centralized creation of integral innovative technological chains (e.g., within state corporations) may become the only possible option. Outsourcing of production of high-tech components and production services is possible only with implementation of new technologies and accumulation of production experience.

3. Active participation of independent small and medium-sized enterprises in innovative development cooperation projects of the high-tech industry is promoted by:

$>$ improvement in temporary competition when implementing innovations, which increases potential losses of "retrograde" enterprises;

$>$ improvement in specialized supplier enterprises' trust in the parent enterprise (the customer), transparency of its innovation strategy;

$>$ execution of contracts with sharing of investments and risks between the customers and suppliers,

$>$ increase in technological similarity of innovative components with the components already produced, and of technologies with the technologies being used (which is impossible when implementing a set of interrelated innovative technologies).

In order to make a quantitative assessment of independent partner enterprises' interest in participation in innovative projects of parent producers of high-tech products, a game-theory model, which takes all the above factors in account, is proposed.

4. Matching of interests of the systems integrators and specialized producers in the course of implementation of innovative technologies and manufacturing of innovative products may be implemented in the form of compensations (advance or conditional), granted by the systems integrator to its potential partners for compensation of potential damages in the course of transition to the innovation strategy. However, with large investments in implementation of innovative technologies, which are comparable with increased profits from their implementation during the planning period, such mechanism becomes inoperable since even in case of success of an innovative project the potential gain in the win may be insufficient to cover the compensation amount. Blackmailing of the project's systems integrator by specialized producers is also possible - they may require payment for their consent to accede to the innovative project, being aware of the fact that in case of the project's failure the integrator would have to pay compensations to all partners, with which it had already entered into relevant agreement.

\section{Acknowledgements}

This research project was supported by the Russian Scientific Fund (RSF Project No. 14-18-00519).

\section{References}

Acemoglu, D., Aghion, Ph., \& Fabrizio, Z. (2002a) Vertical Integration and Distance to Frontier. Journal of the European Economic Association 1 (2-3), 630-638.

Acemoglu, D., Aghion, Ph., \& Zilibotti, F. (2002b) Distance to Frontier, Selection, and Economic Growth. Journal of the European Economic Association 4 (1), 37-74.

Aircraft Manufacturing (2009) Economic Census. Manufacturing. Industry Series. U.S. Census Bureau.

Batkovskiy, A.M., Fomina, A.V., \& Batkovskiy, M.A., et al. (2014) Optimizaciya programmnyh meropriyatii razvitiya oboronnopromyshlennogo kompleksa [Optimization of the Program Activities of the Military-Industrial Complex]. Moscow: Thesaurus [in Russian].

Bogdanova, L.S., Lyashko, E.F., \& Mahitko, V.P. (2006) Finansovo-ekonomicheskii analiz v aviastroenii [Financial and Economic Analysis in the Aircraft Industry]. Ulyanovsk: UISTU [in Russian].

Bonardi, J.-P. \& Warin, T. (2007). Open source software development, innovation and coordination costs. Global Business and Economics Anthology. Vol. 2, 104-116. Business \& Economics Society International, Worcester, MA, USA.

Daft, R. (2004) Organizational Theory and Design. Mason: Thomson South-Western.

Dalle, J-M., \& Julien, N. (2003) "Libre" Software: Turning Fads into Institutions? Research Policy. 32: pp. 1-11.

Dalle, J-M., \& David, P. (2008) Motivation and Coordination in Libre Software Development A Stygmergic Simulation Perspective on Large Community-Mode Projects. DRUID-SCANCOR Conference Paper, Stanford University (March). A revised version of SIEPR Discussion Paper 07-024, December. [Available at: http://siepr.stanford.edu/papers/pdf/07-24.pdf]

Dementiev, V.E. (2012) Rol firm raznyh razmerov na otdelnyh fazah dlinnoi volny [Role of Firms of Different Sizes on the Individual Phases of a Long Wave]. Moscow: Ekonomika i matematicheskie metody [in Russian].

Dubrov, A.M., Lagosha, B.A., \& Hrustalev, E.YU., et al. (2001) Modelirovanie riskovyh situacii v ekonomike $i$ biznese [Modeling of Risk Situations in Economics and Business]. Moscow: Finansy i statistika [in Russian]. 
Dutov, A.V., \& Klochkov, V.V. (2013) Strategicheskoe upravlenie razvitiem aviacionnyh tehnologii: problemy i sovremennye resheniya [Strategic Management of Development of Aviation Technology: Problems and Solutions]. Ekonomicheskii analiz: teoriya $i$ praktika - Economic Analysis: Theory and Practice 48 (351), 2-15 [in Russian].

Glazyev, S.Yu. (1993) Teoriya dolgosrochnogo tehniko-ekonomicheskogo razvitiya [Theory of Long-Term Technical and Economic Development]. Moscow: Vladar [in Russian].

Comer, G. (2001) Lean Manufacturing for the small shop. Dearborn, Ml: Society of Manufacturing Engineers.

Gosudarstvennaya programma Rossiiskoi Federacii "Razvitie aviacionnoi promyshlennosti na 2013-2025 gody [State Program of the Russian Federation "Development of the Aviation Industry in the 2013-2025 Years"]. Retrieved from: http://www.minpromtorg. gov.ru/ministry/fcp/avia2013-2025 [in Russian].

Knobel, A.Yu. (2010) Vertikalnaya integraciya, tehnologicheskaya svjazannost proizvodstv, opportunisticheskoe povedenie i ekonomicheskii rost [Vertical Integration, Technological Connectivity of Facilities, Opportunistic Behavior and Economic Growth]. Ekonomika i matematicheskie metody - Economics and Mathematical Methods 46 (1) [in Russian].

Krayewski, L., \& Ritzman, L. (2004) Operations Management: Processes and Value Chains. Upper Saddle River, NJ: Pearson Prentice Hall.

Kustova, M.V. (2014) Korporativnaya innovacionnaya infrastruktura: opyt "NPO "Saturn" [Corporate Innovation Infrastructure: Experience of Scientific and Production Association "Saturn"]. Retrieved from: Aviaport.ru [in Russian].

Merriam-Webster Online (2005). Merriam-Webster online dictionary. Retrieved November 1, 2005, from http://www.m-w.com

Meyers, F., \& Stephens, M. (2003) Manufacturing Facilities Design and Material Handling. Upper Saddle River, NJ: Pearson Prentice Hall.

Policinskaya, E.V., Sergeeva, D.A., \& Strelkova, T.A. (2014) Analiz i perspektivy razvitiya rossiiskoi aviastroitelnoi otrasli [Analysis and Prospects of Development of the Russian Aircraft Industry]. Mezhdunarodnyi zhurnal prikladnyh i fundamentalnyh issledovanii International Journal of applied and fundamental research 10 (2) $72-75$ [in Russian].

Shcherbakov, D.S. (2010) Koncepciya upravleniya naukoemkim proizvodstvom [The concept of Management of Knowledge-Intensive Production]. Organizator Proizvodstva - Production Organizator 1, 78-85 [in Russian].

Temple, Black J., \& Hunter, S.L. (2003) Lean Manufacturing Systems and Cell Design. Michigan, MI: Society of Manufacturing Engineers.

Udalov, K.G., \& Komissarov, D.S. (1994) Samolet Boing-747. [Boeing-747, the Plane]. Moscow: Aviko-Press.

Ushenin, Y.S. (2015) Importozameshenie na praktike: problemy i zadachi na primere flota [Import Substitution in Practice: Problems and Challenges, the Example of Fleet]. Retrieved from: http://www.odnako.org/blogs/importozameshchenie-na-praktike-problemi-izadachi-na-primere-flota [in Russian].

Volkov, O.I., \& Devyatkin, O.V. (2004) Organizaciya proizvodstva na predpriyatii [Organization of Production of the Enterprise]. Moscow: Infra-M [in Russian].

Wasserman, A.A. (2015) Nesistemnyi podhod: poka u nas sozdayut proizvodstva, no ne promyshlennost [Non-System Approach: While We Create Production, But Not Industry]. Retrieved from: http://www.odnako.org/blogs/nesistemniy-podhod-poka-u-nassozdayut-proizvodstva-no-ne-promishlennost [in Russian]. 